\title{
Infertility and Treatment Seeking Behaviour among Women in Mushin Local Government Area, Lagos State, Nigeria
}

\author{
Chidinma Kenechi Okafor \\ John Lekan Oyefara \\ Michael Kunnuji
}

Department of Sociology

University of Lagos, Nigeria

\begin{abstract}
A paradox in the demographic and epidemiological transitions in sub-Saharan Africa is that as population growth has increased, the rates of infertility have also increased, due to higher rates of sexually transmitted infections (STIs) and earlier age at initiation of sexual intercourse. The majority of married couples desire to have their own biological children, and if they are unable to have children, it is, in most cases, the result of their inability to reproduce. The objective of this study was to examine the social context of infertility treatment seeking behaviour among women in Mushin Local Government Area of Lagos State, Nigeria. Three theories were used to provide explanation for treatment seeking behaviour among women with unmet fertility needs. They include the Health Behaviour model (HBM), theory of stigma and Caldwell's wealth flow theory of fertility. Mixed methods, including a cross-sectional survey and in-depth interview was adopted. The study revealed that nature of infertility and perceived cause of infertility have a significant influence on treatment seeking behaviour among women with unmet fertility needs. A significant number of the respondents visit traditional healers thus these traditional healers should be trained to aid them address the issue of infertility without complications.
\end{abstract}

Keywords: Infertility, treatment seeking behaviour, fertility, Mushin, Lagos State

\section{Introduction}

Infertility can be defined as an inability to conceive after having twelve months of regular unprotected sex (Leonard, 2002). It could be either primary or secondary (Olooto, Amballi \& Banjo, 2012). In primary infertility, the couples have never been able to conceive; while in secondary infertility, there is difficulty in conceiving after having conceived, carried the pregnancy to term or had a miscarriage (Remennick, 2000). A major problem with infertility is that it is yet to be taken seriously as a public health issue (Ibisomi \& Mudege, 2013). It is rather a dark stigma, left on women with unmet fertility needs to solve in the free market of private medicine (Donkor, 2009). This makes them vulnerable to rape by the supposedly care givers, they are exposed to all sort of rituals and could be potential victims of ritual killings (Dyer, 2008), they are also liable to extortion, certain drugs and injections which could be injurious to the reproductive health of these women and the long term effects of these drugs to the general body function are risks associated with modern medicine 
(Nwosu \& Onwe, 2015). There are many barriers to effective and affordable biomedical infertility care in developing countries like Nigeria where some communities suffer poor reproductive health indicators due to more urgent (Abdallah \& Zara, 2001), life-threatening public health issues like maternal mortality and the unmet need for infertility treatment which remains large (Kaadaaga, 2014). Regardless of the medical causes of infertility, women suffer personal grief and frustration, social stigma, ostracism and often serious economic deprivation (Akanbi, 2004). They receive the major blame for reproductive mishaps and in many places infertility is a ground for divorce, causing a woman to lose access to her livelihood and major social networks (Aluko-Arowolo \& Ayodele, 2014). There is also the problem of what and who determines the treatment options used by women with unmet fertility needs.

Infertility could be both a medical and social construct. Health and illness are best understood not as objectively measurable states, but as socially constructed categories negotiated by professionals, affected parties and others in a socio-cultural context (Greil, 2010). The medicalisation of infertility began in earnest with the development of fertility drugs in the USA in the 1950s but it has proceeded even more rapidly since the development of such Assisted Reproductive Technologies (ART) as in vitro fertilisation (IVF) and intracytoplasmic sperm injection (Inhorn \& Van Balen, 2002). This has been described as involving precisely timed actions which include injections of hormones, ejaculation of sperm and cryopreservation of gametes among an interrelated set of actors for example, physicians, nurses and patients to produce a baby in the modern ART clinic (Thompson, 2005).

The social construction of health and illness is perhaps even more striking in the case of infertility than it is for other conditions. The social construction of infertility can be viewed from the following as argued by Slauson-Blevins, 2010:

- No matter how medical practitioners may define infertility, couples do not view themselves as infertile or present themselves for treatment unless they embrace parenthood as a desired role.

- While the biomedical models treat a medical condition as a phenomenon affecting the individual, infertility is often seen as a condition that affects a couple regardless of the partner that has the functional impairment. Thus, defining oneself as infertile involves negotiation between the medical professionals, the couples and the larger social network.

- The presence of infertility is signaled not by the presence of pathological symptoms but the absence of a desired state.

- In the case of infertility as a medical condition other possibilities exist rather than pursuing cure. Such possible alternatives to pursuing cure include self-definition as voluntarily childfree, adoption, fostering or changing partners.

Modernisation has not been able to weaken the deep-rooted tradition of having 
a child as soon as possible after marriage (Ebigbola, 2000). Nigeria's cultural norms and values encourage reproduction and celebrate parenthood. Infertility becomes a potentially stigmatising status, which can adversely affect the identities and interpersonal relationships of married people (Orji, 2002). Despite changes in the last couple of decades in families' living arrangements due to social mobility, modernisation, migration and the effect of globalisation on the family, which has led to growth in single-family housing units and less interference from extended family members, the issue of infertility is still not allowed to be kept private between couples (Ibisomi \& Mudege, 2013). The social meaning of infertility strongly held in Nigeria makes women with unmet fertility needs to be denied their rights (Omage, 2013). Infertility is viewed as being associated with the fact that individuals might have offended the gods and the gods are simply punishing them for their wrong doing (Donkor, 2009). Such disobedience is viewed as women's neglect of ancestors, disrespectful treatment of parents and husbands, eating of certain foods, etc. (Odukogbe, 2009). For example, the mere presence of a woman where a dog is being killed among the Tiv of Benue State, central Nigeria, has an implication for infertility (Ojua, Edem \& Aernyi, 2013). Women with unmet fertility needs are more likely to suffer social consequences of infertility, such as neglect, abandonment, divorce, economic deprivation, social ostracism and physical abuse (Umeora, 2008).

Knowledge and beliefs about treatment behaviour are determined by sociodemographic factors as well as infertility experiences (Tsibulsky, 2012). The factors that explain variation in choice of infertility treatment knowledge are mainly socio-demographic (e.g. age, sex, place of residence, education, employment, country development index) and help-seeking variables such as perceived cause of infertility, duration of infertility, social value of parenthood, etc. (Parry, 2005). Most women with infertility do not usually seek treatment for their problem until between twelve and twenty months into the marriage (Kimani \& Olcnja, 2001). Certain precautionary measures such as avoiding certain food types, drinks or work precede the actual search for solution to the unmet need of infertility (Umezulike \& Efetie, 2004). The husband might be asked to take enough palm wine especially its dregs; it is believed that this enhances the man's power (Nwosu \& Onwe, 2015). A woman begins to seek for treatment against infertility as a result of such factors as in-laws' reactions, threat of second wife, love for children, other women's remarks and social value of parenthood (Nwosu \& Onwe, 2015).

There are many barriers to effective and affordable biomedical infertility care in developing countries like Nigeria where some communities suffer poor reproductive health indicators (Kaadaaga, 2014). Infertility treatment and resources are not widespread in the formal health sector due to more urgent, life-threatening public health issues like maternal mortality, as such unmet need for infertility treatment remains large (Boivin, 1999). As a result, biomedical practitioners are often consulted later when religious and traditional methods have failed to provide a solution to the infertility problem (Kaadaaga, 
2014; Jacob, 2003). The use of traditional herbal medicine has been associated with severe and sometimes fatal complications. However, many infertile women will take on considerable risk to conceive in order to avoid the social and psychological problems associated with childlessness (Peterson, 2006).

Infertility thrives in a social context where access to effective and affordable infertility treatment and management is lacking due to an overall lack of resources and competing health needs (Dyer, 2008). This raises concern on how in the relative absence of appropriate interventions women receive and explain their inability to conceive and the avenues they pursue in order to overcome the status of being infertile (Sundby \& Mboge, 1998). There are various avenues and strategies that men and women may employ which are not related to the health sector. These include feigning pregnancies and miscarriages to avoid the worst of the stigma, claiming pregnancies of other women and polygamy (Hollos, 2003). Other strategies include adoption, surrogacy and fostering of children from relatives (Hollos, 2003). While these coping strategies address some of the negative consequences of infertility, they often do not remove the stigma and may therefore not be solution (Donkor, 2009).

Women with unmet fertility needs face a lot of challenges and have a lot of treatment options at their disposal ranging from traditional, to modern and spiritual. A lot is yet to be done in the area of the manner in which women adopt treatment options as regards infertility; there are also potential risks that are injurious to reproductive health and health generally among these treatment options. This study seeks to unravel a number of puzzles empirically with regards to infertility and treatment seeking behaviour among women. Firstly, this study seeks to explore the relationship between perceived cause of infertility and treatment seeking behaviour among women. Hence the study asks if perceived cause of infertility among women affects treatment seeking behaviour. Secondly, it seeks to explore the relationship that exists between nature of infertility and treatment seeking behaviour. Therefore the study asks, does nature of infertility influences treatment seeking behaviour among women. Thirdly, the study seeks to establish if there is a relationship between duration of infertility and treatment seeking behaviour among women. Hence the study asks, is there an association between duration of infertility and treatment seeking behaviour among women?

\section{Justification for the study}

A major problem with infertility is that it is yet to be taken seriously as a public health issue in sub-Saharan Africa (Ibisomi \& Mudege, 2013). It is rather a dark stigma, left to women with unmet fertility needs to solve in the free market of private medicine (Donkor, 2009). This makes infertile women to be highly vulnerable to rape by the supposedly treatment givers, they are exposed to all sort of rituals and could be potential victims of ritual killings, they are also liable to extortion, certain drugs and injections could be injurious to the reproductive health of these women and the long term effect of these drugs to 
the general body function are risks associated with the modern medicine. With these, it becomes problematic and a thing of concern as to whether there are saturatory orders to regulate and check the excesses' of these forms of treatment and their caregivers. Regardless of the medical causes of infertility, women suffer personal grief and frustration, social stigma, ostracism and often serious economic deprivation (Akanbi, 2004). They receive the major blame for reproductive mishaps and in many places; infertility is a ground for divorce, causing a woman to lose access to her livelihood (Aluko-Arowolo \& Ayodele, 2014). In major parts of Africa, infertility is a major cause of marital disharmony; it exposes women to social discrimination, and physical violence (Greil, 2010). Infertility aggravates the problem of human rights abuse against women, and can lead to socio-economic disempowerment of women (Jacob, 2003).

Infertility strives in a social context where access to effective, affordable infertility treatment and management is inadequate due to an overall lack of resources and competing health needs (Dyer, 2008). It then becomes problematic and raises concern on what factors are considered when selecting a treatment option above the others among women with unmet fertility needs considering the relative inadequate appropriate interventions for infertility as a public health issue. There is also the problem of what and who determines the treatment method used by women with unmet fertility needs. Women go through all kinds of treatments to have a child as a result of social pressure (Aluko-Arowolo \& Ayodele, 2014). In other words, these women are often pressured to be involved in all sorts of treatment options against their will (Koster-Oyekan, 1999). Beliefs about evil spirits and black magic exist strongly among women with unmet fertility needs as a cause of infertility and such beliefs influences their treatment seeking behaviour (Ali, 2006). The social value of parenthood, economic value of children, societal norms and consequences of infertility are general factors that influence treatment seeking behaviour among women with unmet fertility needs. The inadequate intervention on infertility as a public health issue and the associated problems of its treatment within the sub-Saharan Africa context provide essential and urgent justification for this study.

\section{Literature Review}

In Nigeria and other sub-Saharan African countries, having at least one child is crucial to identity formation and the definition of roles within the community (Okonofua, 1999). Parenthood provides an individual with an identity that has both social value and respect (Nwosu \& Onwe, 2015). Having children is one way individuals become recognised in the community, because it brings titles of mother/father and, someday, mother/father-in-law and grandmother/ grandfather in a cultural setting where these roles are much esteemed (Hollos $\&$ Larsen, 2008). An absence of the transition to parenthood often leaves an individual with limited means of earning respect (Boerma, 2001). This is a major reason why women with unmet fertility needs feel belittled and are made 
to feel like a fool (Barden-O'Fallon, 2005). Children are regarded as the light of the family and are important for the continuation of the family and its heritage (Greil, 2010). Children are described as the torchbearers of the family lineage (Ibisomi \& Mudege, 2013). In the absence of children, through whom the lineage is perpetuated, the ancestral light is considered extinguished (AlukoArowolo \& Ayodele, 2014). If there is no child, nothing remains but darkness in life (Leonard, 2002). For those who are unable to have children, there is a strong belief that life has stopped or come to a stop for them (Papreen, 2000). While children are appreciated for many reasons, parents value children most importantly for the security they are expected to provide in old age (Jacob, 2003). A common saying goes thus: 'If there are children, then they give rice and clothing during old age (Riessman, 2000). The achievement of parenthood is regarded as an indispensable condition for the attainment of full development as a complete person to which all aspire (Kimani \& Olcnja, 2001). Apart from the consequences of unmet fertility needs for individuals and their identities, parenthood is a fulfillment of fundamental kinship, religious and political obligations to the community (Koster-Oyekan, 1999). In the cosmology of African societies, children represent a connection to the ancestors and their birth represents a continuation of the family not only in physical but also in religious terms (Boerma, 2001). In subsistence economy, they are also important in providing labour force and economic success has been shown to be correlated with family size (Johnson-Hanks, 2006). A summary of reasons for having children in sub-Saharan Africa includes: (1) social security desire - in which children are seen as necessary for the families survival and for the support of parents at old age, (2) social power desire - in which children are considered a valuable power source, especially for women in patriarchal social relations and (3) social perpetuity desire - in which children fulfill the need to continue group structures into the future and to connect them to the past (Inhorn \& Van Balen, 2002).

Children are considered a source of happiness to the family and tighten the bond between spouses; infertility thus destroys peace for both men and women (Araoye, 2003). Women with unmet fertility needs may feign pregnancy in an attempt to protect themselves from being abandoned by their husbands; and suffer social rejection and marginalisation by their communities (Nwosu \& Onwe, 2015). In some communities women with unmet needs were held responsible for epidemics like chicken pox and cholera, while in some others, they are not allowed to touch other women's children (Olooto, Amballi \& Banjo, 2012). Women with unmet fertility needs are often divorced, have multiple life-time partners, and are therefore predisposed to have sexual intercourse with fertile partners at some point in their life (Mgalla, 1999). The following were some of the experiences of women with infertility: negative identity; a sense of worthlessness and inadequacy; a feeling of lack of personal control; anger and resentment; grief and depression; anxiety and stress; lower life satisfaction; envy of other mothers; loss of the dream of co-creating; the 'emotional roller coaster'; and a sense of isolation (Williams, 1997). Women 
experience infertility as an unexpected life-course disruption (Ulrich \& Weatherall, 2000). There is this sense among infertile women that time is slipping away and this time varies among various societal timetable types, body timetable and treatment timetable (Martins \& Mathews, 2001). This mode of viewing time among women tends to put them on the receiving end of the effect of infertility than the men.

Infertility treatment seeking behaviour can be influenced by attitudes towards infertility medical consultation and treatment, especially if such attitudes prevent people from seeking the desired help. Negative beliefs about the safety, accessibility and cost of infertility treatment have been reported (Boivin, Bunting, Collins \& Nygren, 2007). Normative, moral or cultural beliefs also affect infertility treatment seeking behaviour (Dyer, 2008). Conversely or overly optimistic attitudes about treatment success rates could affect the start of treatment efforts. Attitudes towards infertility treatment are often dependent on the characteristics of the patient, doctor and context (Tschudin, 2010). Country of origin also seems to be an important contextual factor when considering knowledge and beliefs about infertility. For example, American samples tend to attribute infertility problems to biomedical and chance factor, whereas in Nigeria infertility is still attributed to supernatural causes (Aladekomo, Oludar \& Ola, 2008). Access to ART is limited. The generally high cost of ART procedures and national policies regarding accessibility and reimbursement leave many women with infertility incapable of going through ART (Vayena, Rowe \& Griffin, 2001).

According to WHO's findings, the most prevalent disorders (36\%) are tubal diseases resulting primarily from inflammation (WHO, 2010). For a woman, infertility can manifest itself as either the inability to become pregnant, an inability to maintain a pregnancy, or an inability to carry a pregnancy to a live birth (WHO, 2010). Infections constitute the most important and most preventable cause of infertility (Abdallah \& Zara, 2001). Primary infertility among women is generally the result of infections associated with sexually transmissible diseases (STDs); secondary infertility could be as a result of postabortal or postpartum infection, with a smaller contribution from STDs (Blundell, 2007). A lack of fertility awareness among women seeking infertility treatment may increase the duration of infertility before they seek medical help (Swift \& Liu, 2014). Women are generally expected to know more about infertility than men because they tend to be first to consult their physician about infertility problem and have more direct infertility experiences through their menstrual cycle (Swift \& Liu, 2014). The experience of treatment seeking itself could impact on fertility knowledge and beliefs. For example, preparatory clinic information provided prior to infertility clinic appointments has been shown to increase the knowledge of infertility and increase attendance at clinic appointments (Pook \& Krause, 2005). Other individual factors such as education, socioeconomic status are likely to affect awareness about fertility (Hawkins, 2007). 


\section{Theoretical Orientation}

In this study, the theory of stigma, the health belief model and fertility theory were selected to show the relationship that exists between infertility treatment seeking behaviour and certain factors. It also helped to buttress the level of influence such factors wield on infertility treatment seeking behaviour among women.

\section{Theory of Stigma}

Goffman as cited in (Ritzer, 2006) defines stigma as the situation of the individual who is disqualified from full social acceptance and any attribute that is deeply discrediting. Stigmatised people are those that do not have full social acceptance and are constantly striving to adjust their social identities: physically deformed people, mental patients, drug addicts, prostitutes, etc. In gaining deeper epistemic understanding of stigma, it is imperative to note that rather than focusing solely on the stigmatised attribute, a proper understanding of the social relationships that transform a simple characteristic into a fullyfledged stigma is inevitable. A language of relationships, which moves beyond the individual and emphasises the socially-contingent nature of stigma, is essential in buttressing our understanding of stigma. Another key element of stigma, as Goffman understands it, is that the bearer must have some sort of concern for what others think, and must internalise the social norms to which they fail to conform. Goffman indicated that stigma is in some ways contextual and relational. This implies that certain characteristics that attract negative attention and discrimination in one circumstance may in fact be positive or normative in a different circumstance, although certain characteristics are viewed so negatively that in a particular socio-cultural milieu they will always be abnormal and deviant.

From this theory, women with unmet fertility needs firstly have some sort of concern for what others feel about their status and work towards correcting such feelings. The level of internalization of such feelings exposes them to domestic violence and the quest for treatment seeking. Such feelings get them stigmatised because they are seen as deviants from the shared norm of procreation within the society. If the stigmatisation women with unmet fertility needs experience is on the high side, then the search for treatment options to break loose from such a stigma will automatically be high. A major weakness of this theory is that it focuses on the stigmatised rather than the stigmatisers. This has variously been criticised for framing stigmatised individuals as victims thereby stripping them of agency; for 'victim-blaming'. The theory was also criticised for not drawing enough attention to the broader, social-structural concerns that lead to stigmatisation.

\section{Health Belief Model}

The Health Belief Model (HBM) is a psychological model that attempts to explain and predict health behaviour. This is done by focusing on the attitudes and beliefs of individuals. The HBM was first developed in the 1950 s by social 
psychologists Rosenstock and Kegels (Rosenstock, 1974). Action in the HBM is guided by (i) belief about the impact of illness and its consequences (threat perception); (ii) health motivation i.e. readiness to be concerned about health matters; (iii) belief about the consequences of health practices (Behavioural Evaluation); (iv) cues to action, which include internal and external factors; and (v) conditions such as socio-demographic and psychological characteristics of the affected person.

The HBM is evaluated in terms of four constructs representing the perceived threat and net benefits; these are perceived susceptibility, perceived severity, perceived benefits and perceived barriers. These concepts were proposed as accounting for people's readiness to act and respond to treatment. The HBM model also grouped key factors for health seeking behaviour into "four As"; they are:

- Availability: refers to the geographical distribution of treatment outlets, pharmaceutical products etc.

- Accessibility: includes transport, roads etc.

- Affordability: includes treatment costs for the individual, household, or family. A distinction is made between the direct, indirect and opportunity cost of health services.

- Acceptability: refers to cultural and social distance. This mainly refers to the characteristics of the treatment providers, health workers' behaviour, the gender aspect (non acceptance of being treated by the opposite sex, in particular women who refuse to be seen by male nurses/doctors), excessive bureaucracy, etc.

The model is suitable for this paper in that it has been able to shed more light on the health seeking behaviour of affected individual, irrespective of the consequence of infertility. If certain factors such as the $4 \mathrm{~A}$ 's postulated by the HBM model are not readily available women with unmet fertility needs will be unable to reach out to receive any form of infertility treatment available. In other words if the perceived threat of a particular treatment option is lower than its net benefits, women with unmet fertility needs will be geared towards such a treatment option. Although the HBM may be used to derive information that may then prompt interventions designed to change health beliefs and behaviour, using the model itself cannot inform decision making as to how such interventions might best be structured. As a result, the value of the 'perceived threat' element which is the major indicator of behavioural motivation in the HBM has been questioned.

\section{Caldwell's Wealth Flow Theory of Fertility}

John Caldwell's wealth flow theory proposes a direct link between family structure and fertility (Caldwel, 1976). According to the theory, there are only two major forms of family structure, differing principally in the direction of wealth flow among generations. In 'primitive' and 'traditional' societies, net wealth flow are primarily in an upward direction from younger to older 
generations, and individual interests are subjugated to corporate interests. In developed nations, family structure is organised in terms of downward wealth flow where parents are expected to provide for children's economic well-being. The theory proposes that fertility decisions in all societies are economically rational responses to familial wealth flow patterns. In societies with a net upward wealth flow, the economically rational decision is to have as many surviving children as possible (within the constraints imposed by biology), because each additional child adds positively to a parent's wealth security in old age, as well as their social and political well-being. In societies with a net downward wealth flow, the economically rational decision is to have no children or the minimum number allowed by a psychological disposition that derives pleasure from children and parenting.

This theory is suitable for this paper because it has been able to shed more light on the economic value of having children. If women with unmet fertility needs have a great veneration towards the economic value of having children, the quest and desire for treatment seeking will be high also. In Nigeria for instance where old age security is non-existent, the economic value of children becomes a major push towards treatment seeking among women with unmet fertility needs. This theory has been criticised for its upward wealth flow, in all human organism wealth flow is downward from parents to their children as argued by the evolutionary biologists because parents will always provide for their children until they get to a certain stage.

\section{Methods and Data}

\section{Research Design, Study Location and Population}

The non-experimental research design which consists of cross-sectional survey and the ethnographic method of conducting in-depth interviews were used to generate data for this study. The reason for this was to generate both the qualitative and quantitative information concerning the topic under study. Mushin which is a Local Government Area in Lagos State, Nigeria was selected for the study. It is located $10 \mathrm{~km}$ north of the Lagos city core, adjacent to the main road to Ikeja. It is largely a congested residential area with inadequate sanitation and low-quality housing. It had 633,009 inhabitants at the 2006 Census. Mushin is within the Lagos Metropolitan Area. The study population for the quantitative technique comprised of married women within the age bracket of 20-49 years with unmet fertility needs, while the qualitative methods focussed on both women with unmet fertility needs and stakeholders on infertility treatment.

\section{Sample Size and Sampling Techniques}

The study utilised data generated from a cross-sectional survey and in-depth interviews. The questionnaires used in the survey were administered to married women with unmet infertility needs. A total of 117 women with unmet fertility needs were interviewed in the cross-sectional survey. The qualitative method adopted for the study (i.e. the in-depth interviews) focused on women with 
unmet fertility needs, key informants (traditional/modern fertility care givers). The reason for selecting these groups of people for the qualitative study was for them to air their opinions on the theme of the study. In general a total number of 13 in-depth interviews were conducted in the study. This consisted of 11 women with unmet fertility needs, 1 herbal Medicare giver and 1 medical doctor. Snow balling and purposive sampling techniques were used to select the respondents. These methods are based on convenience, relevance and referrals of the respondents based on the theme of study. The interviews were conducted in private, at the respondents' homes. English language and pidgin were used. Respondents had a wide range of infertility experiences including primary infertility, secondary infertility, past fertility problems that have since been resolved and no fertility problems whatsoever. Selection criteria included ages between 20 and 60 years, women who had either had a live birth or attempted to get pregnant.

\section{Research instruments}

A standardised questionnaire containing questions on respondents' background information, and several themes including perceived cause of infertility, nature of infertility, sexual history and behaviour of the respondents, knowledge on treatment options, and knowledge on the impact of sexual transmitted infection on fertility was administered to all the respondents in face-to-face interviews using the snow balling sampling technique. Only respondents who supplied usable answers to key questions were processed for analysis. The questionnaires were administered to the study population through the personal interview method (interviewer-administered technique). In the in-depth interview session, 13 unstructured interview guides (questions) was used as the research instrument.

\section{Method of Analysis}

Quantitative data were analysed using the Statistical Package for Social Sciences, Version 23. The simple frequency and percentage analysis was used in the description of the background characteristics of respondents, the nature of infertility, perceived cause of infertility, knowledge on treatment options and knowledge on the impact of sexual transmitted infection on fertility at the univariate level. The quantitative data at the bivariate level were analysed using Chi square $\left(\chi^{2}\right)$ statistical method. At the multivariate level, the logistic regression statistical analysis method was utilised while a thematic analysis method of the qualitative data was adopted using content analysis technique.

\section{Ethical Consideration}

Informed consent was sought and obtained from the respondents. All interviews were conducted outside hearing distance of third parties. 


\section{Results}

\section{i. Socio-demographic Characteristics of Respondents}

The socio-demographic background factors of the respondents can be seen on Table 1. As presented in the table, the minimum and maximum ages of the respondents are 20 and 49 years while the mean age was 32.4 years. The respondents were categorised into two stages based on age. The first category comprised young women within the age bracket of twenty to thirty-four years. This category of women accounts for 58.1 per cent of the sample. The second category was made up of older women who were still seeking treatment to conceive (35-49 years) accounts for 41.9 per cent of the respondents. About 88.0 per cent of the respondents had acquired some form of formal education at various levels up to the tertiary level. More than 60.1 per cent of the subjects had completed secondary school (i.e. twelve years of formal education) and some had higher qualifications. 9.7 per cent of the subjects never acquired formal education. Among these people some were apprentices; some were gainfully employed while others were unemployed at the time of the study. About 75.0 per cent of the respondents were in monogamous marriage at the time of the study. 
Table 1: Percentage Distribution of Respondents by their Sociodemographic Background Factors

\begin{tabular}{|c|c|c|}
\hline Sociodemographic Factors & Frequency & Percentage \\
\hline \multicolumn{3}{|l|}{ Age } \\
\hline $20-24$ & 15 & 12.8 \\
\hline $25-29$ & 23 & 19.7 \\
\hline $30-34$ & 30 & 25.6 \\
\hline $35-39$ & 20 & 17.1 \\
\hline $40-44$ & 18 & 15.4 \\
\hline $45-49$ & 11 & 9.4 \\
\hline \multicolumn{3}{|l|}{ Ethnic background } \\
\hline Hausa & 11 & 9.4 \\
\hline Igbo & 34 & 29.1 \\
\hline Yoruba & 63 & 53.8 \\
\hline Others (Isoko, Igala, Urhobo, Ijaw etc) & 9 & 7.7 \\
\hline \multicolumn{3}{|l|}{ Ever attended school } \\
\hline Yes & 103 & 88.0 \\
\hline No & 14 & 12.0 \\
\hline \multicolumn{3}{|l|}{ Highest level of education } \\
\hline Primary & 22 & 21.3 \\
\hline Secondary & 40 & 38.8 \\
\hline Tertiary & 31 & 30.1 \\
\hline Others & 10 & 9.7 \\
\hline \multicolumn{3}{|l|}{ Religious affiliation } \\
\hline Christianity & 81 & 69.2 \\
\hline Islam & 27 & 23.1 \\
\hline Traditional & 3 & 2.6 \\
\hline $\begin{array}{l}\text { Others (Grail Message, Hinduism, } \\
\text { Eckankar etc.) }\end{array}$ & 6 & 5.1 \\
\hline \multicolumn{3}{|l|}{ Employment Status } \\
\hline Employed & 62 & 53.0 \\
\hline Not employed & 55 & 47.0 \\
\hline \multicolumn{3}{|l|}{ Form of marriage } \\
\hline Monogamy & 88 & 75.2 \\
\hline Polygyny & 29 & 24.8 \\
\hline Total & 117 & 100.0 \\
\hline
\end{tabular}

\section{ii. History of Sexual Behaviour of Respondents before Marriage}

Respondents were asked some retrospective questions about the history of their sexual life before marriage and their responses to these questions were on Table 2. From the table, 65.8 per cent of the respondents were sexually active before marriage, while only 26.5 per cent were not sexually active. From the table also, the proportion of women protecting themselves against pregnancy $(74.0 \%)$ and sexually transmitted infections $(81.0 \%)$ was high, hence the lower number $(18.1 \%)$ of respondents who had ever contracted STIs. Furthermore, about 16.0 per cent of the sexually active women before marriage had ever 
procured induced abortion.

Table 2: Percentage Distributions of Respondents by History of their Sexual Behaviour before Marriage

\begin{tabular}{|l|l|l|}
\hline Sexually active before marriage & Frequency & Percentage \\
\hline Yes & 77 & 65.8 \\
\hline No & 31 & 26.5 \\
\hline No response & 9 & 7.7 \\
\hline Total & 117 & 100.0 \\
\hline Protected self from pregnancy while having sex & & \\
\hline Yes & 57 & 74.0 \\
\hline No & 20 & 26.0 \\
\hline Total & 77 & 100.0 \\
\hline Protected self from STIs & & \\
\hline Yes & 62 & 81.0 \\
\hline No & 15 & 19.0 \\
\hline Total & 77 & 100.0 \\
\hline Ever contracted STIs & & \\
\hline Yes & 14 & 18.1 \\
\hline No & 63 & 81.8 \\
\hline Total & 77 & 100.0 \\
\hline Ever had Induced Abortion & & \\
\hline Yes & 12 & 15.6 \\
\hline No & 65 & 84.4 \\
\hline Total & 77 & 100.0 \\
\hline
\end{tabular}

\section{iii. Current Sexual Behaviour of Respondents in Marriage}

Sampled infertile women were further asked about their current sexual behaviour in marriage most especially with their spouses. Answers to the various questions asked can be seen on Table 3. From the table, 78.7 per cent of the respondents were sexually active with their spouses; while a few (18.8\%) of the respondents claimed that their husbands deny them sex. In addition, about 23.0 per cent of the respondents persuade their husbands to have sexual intercourse with them. Despite the quest to have children, available data on the table suggest that some women still have issues with the sexual behaviour of their spouses. In a situation where the husband was not motivated to have regular unprotected sexual intercourse with their wives, the proportion of the fecundability within an ovulatory cycle will be significantly minimal. 
Table 3: Percentage Distributions of Respondents by their Current Sexual Behaviour in Marriage

\begin{tabular}{|l|l|l|}
\hline Number of times respondent has sex a week & Frequency & Percentage \\
\hline Once & 9 & 7.7 \\
\hline Twice & 32 & 27.4 \\
\hline Thrice & 38 & 32.5 \\
\hline Four times & 22 & 18.8 \\
\hline Five times and above & 5 & 4.3 \\
\hline No response & 11 & 9.4 \\
\hline Respondent's husband denies her sex & & \\
\hline Yes & 22 & 18.8 \\
\hline No & 85 & 72.6 \\
\hline No response & 10 & 8.5 \\
\hline Respondent persuades husband to have sex with her & & \\
\hline Yes & 27 & 23.1 \\
\hline No & 80 & 68.4 \\
\hline No response & 10 & 8.5 \\
\hline Total & 117 & 100.0 \\
\hline
\end{tabular}

\section{iv. Perception of Respondents about the Causes of Infertility}

Respondents were asked about their perception about the causes of infertility and their responses were presented on Table 4 . From the table, majority of the respondents $(59.8 \%)$ perceived that health issues were responsible for their inability to conceive. The table also revealed that although majority of the respondents believed that health issues were majorly responsible for their inability to conceive, quite a number $(39.3 \%)$ of the respondents still believed that infertility can be inflicted on a woman by virtue of punishment or causing harm to her; quite a number (38.5\%) of them believed that infertility can be caused by spiritual forces. This confirms the literature that takes the position that beliefs about evil spirits and black magic exist strongly among infertile women as a cause of infertility and such beliefs affect their treatment seeking behaviour (Ali, 2006). 
Table 4: Percentage Distributions of Respondents by Perceived Causes of Infertility

\begin{tabular}{|l|l|l|}
\hline $\begin{array}{l}\text { Respondent's opinion on factors responsible for their } \\
\text { inability to conceive and have a live birth as desired }\end{array}$ & Frequency & Percentage \\
\hline My past life & 29 & 24.8 \\
\hline Health issues & 70 & 59.8 \\
\hline My husband is not sexually active & 10 & 8.6 \\
\hline Spiritual forces & 8 & 6.8 \\
\hline $\begin{array}{l}\text { Whether infertility be inflicted on one as a result of } \\
\text { punishment or harm }\end{array}$ & & \\
\hline Yes & 64 & 54.7 \\
\hline No & 46 & 39.3 \\
\hline No response & 7 & 6.0 \\
\hline Whether infertility be caused by spiritual forces & & \\
\hline Yes & 67 & 57.3 \\
\hline No & 45 & 38.5 \\
\hline No response & 5 & 4.3 \\
\hline Total & 117 & 100.0 \\
\hline
\end{tabular}

\section{v. Infertility Treatment Options Ever Used by Respondents}

Data on infertility treatment options ever used by respondents can be seen on Table 5. As presented in the table, the difference between respondents who have tried modern (43.6\%) and traditional $(35.0 \%)$ method of infertility treatment is not significant $(8.6 \%)$. Type of drugs used by respondents also reveals that herbal drugs (42.8\%) also complement modern drugs (57.2\%); this confirms a simultaneous use of both modern and herbal drugs among the respondents. On adherence to drug dosage, majority of the respondents $(90.6 \%)$ adhere strictly to the prescribed dosage, while only very few $(9.4 \%)$ do not. These confirm the literature that women sometimes visit the hospital and the traditional infertility healer simultaneously (Nwosu \& Onwe, 2015). Among respondents who have tried the alternative method, those who have adopted child fostering had the highest percentage $55.6 \%$, while those who have adopted children had $39.3 \%$. Surrogacy appears to still be alien and expensive hence its very low percentage $1.7 \%$. 
Table 5: Percentage Distributions of Respondents by Treatment Options Ever Used

\begin{tabular}{|l|l|l|}
\hline $\begin{array}{l}\text { Nature of infertility treatment method tried by } \\
\text { respondent }\end{array}$ & Frequency & Percentage \\
\hline Traditional & 41 & 35.0 \\
\hline Modern & 51 & 43.6 \\
\hline Spiritual & 25 & 21.4 \\
\hline Nature of fertility drugs used by respondents & & \\
\hline Herbs & 50 & 42.8 \\
\hline Modern drugs & 67 & 57.2 \\
\hline Do respondents adhere strictly to drug dosage & & \\
\hline Yes & 106 & 90.6 \\
\hline No & 11 & 9.4 \\
\hline Alternative method tried by respondent & & \\
\hline Surrogacy & 2 & 1.7 \\
\hline Child fostering & 65 & 55.6 \\
\hline Adoption & 46 & 39.3 \\
\hline Others & 3 & 2.6 \\
\hline No response & 1 & 0.8 \\
\hline Total & 117 & 100.0 \\
\hline & & \\
\hline
\end{tabular}

\section{vi. Bivariate Analyses of Key Infertility Variables and Nature of Treatment Adopted}

As noted in the previous section, infertile women majorly adopt three major treatment techniques to cure their inability to reproduce in the study location. These techniques are traditional, modern and spiritual. In this section of the paper, three key infertility variables were cross-tabulated with the nature of infertility treatment adopted by the women. The three variables are perception about the causes of infertility, nature of infertility (primary or secondary) and duration of infertility. The outcomes of these analyses are presented respectively in the next sub-sections.

\section{a. Perception about the Cause of Infertility and Nature of Treatment Adopted}

As presented in Table 6, the study shows that there is a significant relationship between perception of infertility and treatment seeking behaviour among women (with $\mathrm{P}<0.05$ ). Extracts from the in-depth interviews complements the findings from the survey data as a many of interviewees revealed that their inability to conceive can only be attributed to health issues.

I have been trying to get pregnant over 5 years now after my first child and the doctor said I cannot get pregnant again because my cervices can no longer open. They are not blocked, but they just cannot open again. (IDI/Secondary infertility/40years/9years marriage/lchild) 
My husband has a low sperm count, but doctors says he still has chances of fathering more children. (IDI/Secondary infertility/ 36years/10years marriage/lchild)

I have not been able to conceive because I have an irregular ovulation and my husband who is diabetic has erectile dysfunction. (IDI/Primary infertility/38years/8years marriage)

These extracts revealed the role of health factors in the incidence of infertility among married women in the study location. Key informant interviews on the perceived cause of infertility further revealed the following:

Infertility can be caused by spiritual forces especially through dreams; those that eat in the dream are majorly victims of this. So when they come, I see that their problem is spiritual and pray for them. When I see them, I also know whether the cause of infertility is as a result of spiritual husband. After I have broken the bond between them and their spirit husband I get to be attacked in the dream by the spiritual husband. Some infections like staphylococcus, makes a man's sperm watery, weak and low in number. This prevents him from being able to impregnate his wife and will also transfer the infection to the wife. Infections in the womb can seem to move like a baby kicking in the womb and can even enlarge the stomach to seem like pregnancy. Some women do visit wrong places where they are given medications not meant for them. It causes the womb to be hot and it blocks the fallopian tube. The membrane that raptures before a baby comes out can also cause infertility in a woman. The water has to leave the body of the woman properly, because it could prevent her from taking in a second time. This water also causes stomach upset and it is only herbal medicare givers that know about this. When they come, I touch their stomach and see that there is water in their womb, and then I give them roots to take. Also, when touching them, I get to know whether their husbands have low or watery sperm count. The herbs are applied by taking a shot of it in the morning and evening. The various positions used in the course of sexual intercourse can also shift the womb from its actual position. The length of the penis can also disrupt the position of the womb thereby causing infertility in the woman. To adjust the womb back to its normal position we massage using two fingers through the vagina. It is a process. (KII/Herbal care giver/Ijaw woman) 
Table 6: Percentage Distribution of Respondents by Key Variables of Infertility and Nature of Treatment Adopted

\begin{tabular}{|l|l|l|l|l|}
\hline \multirow{2}{*}{ Key Infertility Variables } & \multicolumn{3}{|c|}{ Nature of Infertility Treatment Method Adopted } \\
\cline { 2 - 5 } & $\begin{array}{l}\text { Modern } \\
(\%)\end{array}$ & $\begin{array}{l}\text { Traditional } \\
(\%)\end{array}$ & $\begin{array}{l}\text { Spiritual } \\
(\%)\end{array}$ & Total (\%) \\
\hline Perceived Cause of Infertility & & & & \\
\hline $\begin{array}{l}\text { Previous sexual infection } \\
\text { history }\end{array}$ & $16(55.2)$ & $7(24.1)$ & $6(20.7)$ & $29(100.0)$ \\
\hline Health issues & $17(24.3)$ & $39(55.7)$ & $14(20.0)$ & $70(100.0)$ \\
\hline Irregular sex with husband & $4(40.0)$ & $4(40.0)$ & $2(20.0)$ & $10(100.0)$ \\
\hline Spiritual forces & $4(50.0)$ & $1(12.5)$ & $3(37.5)$ & $8(100.0)$ \\
\hline Total & $41(35.0)$ & $51(43.6)$ & $25(21.4)$ & $117(100.0)$ \\
\hline$\chi^{2}=13.978$, d.f. $=6, \mathrm{P}=0.030$ & & & & \\
\hline Nature of Infertility & & & & $13(19.7)$ \\
\hline Primary infertility & $33(50.0)$ & $20(30.3)$ & $66(100.0)$ \\
\hline Secondary infertility & $8(15.7)$ & $31(60.8)$ & $\begin{array}{l}12 \\
(23.5)\end{array}$ & $51(100.0)$ \\
\hline Total & $41(35.0)$ & $51(43.6)$ & $\begin{array}{l}25 \\
(21.4)\end{array}$ & $117(100.0)$ \\
\hline$\chi^{2}=15.996$, d.f. $=2, \mathrm{P}=0.000$ & & & & \\
\hline Duration of Infertility & & & & \\
\hline $1-10$ & $37(37.4)$ & $41(41.4)$ & $21(21.2)$ & $99(100.0)$ \\
\hline $11-20$ & $4(22.2)$ & $10(55.6)$ & $4(22.2)$ & $18(100.0)$ \\
\hline Total & $41(35.0)$ & $51(43.6)$ & $25(21.4)$ & $\begin{array}{l}117 \\
(100.0)\end{array}$ \\
\hline$\chi^{2}=1.704 ;$ d.f. $=2 ; \mathrm{P}=0.427$ & & & & \\
\hline
\end{tabular}

A gynecologist during the key informant interview at a teaching hospital has this to say about the causes of infertility:

A lot of factors can cause infertility in a woman they include; Age: The older a lady gets the more the ova reduces and deteriorates Anovulation: This is caused as a result of hormonal imbalance in a woman which leads to failure of ovulation. Under this, we have; hyperprolactinemia - high levels of prolactin, which is the hormone that produces breast milk. Polycystic ovarian syndrome- in this case, the follicles are just arrested and not developing. Poorly/underdeveloped ovaries-The ovaries are not properly developed and this comes from birth. There is no clear judgment on whether there is a relationship between fibroid and infertility because often times when the fibroid is removed, women get to take in. When asked if infertility is hereditary - Yes, infertility is hereditary through Polycystic ovarian syndrome (PCOS). This affects females alone. The carrier is multifactorial. In other words, some from the father and the mother. The hereditary pattern though remains uncertain. (KII/ Obstetrics and Gynecologist/LUTH) 


\section{b. Nature of Infertility and Method of Treatment Adopted}

In Table 6, this study shows that there is a significant relationship between nature of infertility and treatment seeking behaviour (with $\mathrm{P}<0.05$ ). At the level of the in-depth interview, the respondents were asked about the infertility treatment method they have used on the basis of whether they had the primary or secondary infertility and the following was extracted.

After two years into the marriage without conception, I started desiring to have children. I was having pains in my tummy initially, so I complained to a doctor who referred me to a gynecologist who said it was because I was not ovulating. He gave me a drug called colmade and I observed it was an over dose because I'm a chemist. This discouraged me to continue with any infertility treatment further. So, I sought for herbal treatment, where I was told fibroid was responsible for the pains. I was placed on the herbal drugs and 3months into the herbal treatment, the pains disappeared. I was on this herbal drug for a year before I eventually became pregnant. (IDI/Secondary infertility/36years/10years marriage/1 child)

Other women that had been infertile for some years explained the nature of infertility treatment they had adopted thus:

I have tried several methods ranging from spiritual to traditional and modern. On the Spiritual methods-I have visited a lot of prayer homes when I decided to go spiritual using prayers. Traditionally - I have visited several herbal medicare givers. On one occasion, the herbal woman inserted her hand into my vagina, to check whether my womb was well placed. This was used to determine the herbs she gave me. Medically - I have tried IUI (Intra uterine insemination), IVF (in-vitro fertilisation), I have been on series of ovulation stimulating drugs, that I had to reduce it for fear of contracting cancer. (IDI/Primary infertility/ 33years/5years marriage)

I have tried several methods ranging from spiritual, to traditional and modern. Traditionally- I have taken all sorts of herbs prescribed by various herbal care givers of various portion. I do not know the names of the herbs. Spiritually-I have visited several houses of prayer and native doctors. On my visit to one of the native doctors, I was told to bring a goat with some other things. I was told to kill the goat with my bare hands. After which the content was put in a bowl and given to me to carry with the native doctor to a stream at night. There I was bathed with the water and the bowl was deposited on the water. Medically-I have been on fertility drugs for as long as I started looking for babby, I have tried artificial insemination also. I have 
done virtually everything to get pregnant but I have never missed my period or had a miscarriage. (IDI/Primary infertility/46 years/26years marriage)

\section{c. Duration of Infertility and Method of Treatment Adopted}

In Table 6 there are data on the relationship between duration of infertility and treatment method adopted by infertile women in the study location. This table reveals that the calculated value $\left(\chi^{2}\right)$ is 1.704 and the P-value is 0.427 , which is greater than the level of significance of 0.05 . This implies that there is no significant relationship between duration of infertility and treatment seeking behavior of the women. There is also the idea that time is slipping away on the part of any woman with unmet fertility needs because of menopause. Time is of essence, so the pressure to conceive remains indispensable regardless of the duration of infertility.

\section{vii. Mutivariate Analysis of Sociodemographic Factors and Adoption of Modern Infertility Treatment}

The multivariate binary logistic regression on Table 7 revealed that respondents with secondary education are more likely to use modern fertility treatment methods compared to respondents with no formal education. Respondents with secondary education were more than 7 times more likely to use modern infertility treatment methods compared to respondents with no formal education.

With respect to religion, results from the regression analysis reveals that the odds of Muslims using the modern infertility treatment method compared to Christians is 3.431 . This means that Muslims are more than three times more likely to use modern infertility treatment options compared to Christians. Results from the logistics regression model showed that respondents between the ages of 45 and 49 years are less likely to use modern infertility treatment methods compared to respondents between the ages of 20 and 24 years. The odds of respondents between the ages of 45 and 49 years using modern infertility treatment methods compared to respondents between the ages of 20 and 24 years is .045 . This implies that the likelihood of respondents between the ages of 45 and 49 years using modern infertility treatment methods compared to respondents between the ages of 20 and 24 years is less than half. 
Table 7: Binary logistic regression showing predictors of use of modern method of infertility treatment

\begin{tabular}{|c|c|c|c|c|c|}
\hline \multirow{2}{*}{$\begin{array}{l}\text { Sociodemographic } \\
\text { Factors }\end{array}$} & \multirow[b]{2}{*}{ B } & \multirow[b]{2}{*}{ S.E } & \multirow[b]{2}{*}{$\begin{array}{l}\text { Exp. } \\
\text { (B) }\end{array}$} & \multicolumn{2}{|c|}{ 95\% C.I FOR EXP(B) } \\
\hline & & & & LOWER & HIGHER \\
\hline \multicolumn{6}{|l|}{ Educational status } \\
\hline None (RC) & & & 1.0 & & \\
\hline Primary & -0.607 & 1.347 & 0.545 & 0.039 & 7.635 \\
\hline Secondary & 1.986 & 1.152 & $7.286^{*}$ & 0.763 & 69.612 \\
\hline Tertiary & 1.562 & 1.025 & 4.768 & 0.639 & 35.558 \\
\hline \multicolumn{6}{|l|}{ Religion } \\
\hline Christianity(RC) & & & 1.0 & & \\
\hline Islam & 1.233 & .617 & $3.431^{*}$ & 1.023 & 11.504 \\
\hline Traditional & -0.687 & 1.299 & 0.503 & 0.039 & 6.420 \\
\hline \multicolumn{6}{|l|}{ Age Range } \\
\hline 20-24years (RC) & & & 1.0 & & \\
\hline $25-29$ years & 0.833 & 0.905 & 2.301 & 0.390 & 13.572 \\
\hline 30-34years & 0.280 & 0.856 & 1.324 & 0.247 & 7.079 \\
\hline 35-39years & -0.443 & 0.968 & 0.642 & 0.096 & 4.283 \\
\hline 40-44years & 0.085 & 0.952 & 1.089 & 0.168 & 7.037 \\
\hline 45-49years & -3.097 & 1.389 & $0.045^{*}$ & 0.003 & 0.687 \\
\hline \multicolumn{6}{|l|}{ Nature of infertility } \\
\hline Primary (RC) & & & 1.0 & & \\
\hline Secondary & -1.196 & 0.514 & $0.302 *$ & 0.110 & 0.828 \\
\hline \multicolumn{6}{|l|}{$\begin{array}{l}\text { Perceived Causes of } \\
\text { infertility }\end{array}$} \\
\hline $\begin{array}{l}\text { Previous sexual } \\
\text { Infection history (RC) }\end{array}$ & & & 1.0 & & \\
\hline Health Issues & 1.549 & 0.686 & $4.706^{*}$ & 1.226 & 18.063 \\
\hline $\begin{array}{l}\text { Irregular sex with } \\
\text { husband }\end{array}$ & 1.391 & 1.005 & 4.021 & 0.561 & 28.800 \\
\hline Spiritual forces & 0.869 & 0.990 & 2.385 & 0.343 & 16.614 \\
\hline \multicolumn{6}{|l|}{ Duration of infertility } \\
\hline 1-10years (RC) & & & 1.0 & & \\
\hline 11-20years & 0.462 & 0.741 & 1.587 & 0.371 & 6.781 \\
\hline Constant & -2.107 & 1.377 & 0.122 & & \\
\hline Model $X^{2}(p)$ & $42.558(0.000)$ & & & & \\
\hline $\begin{array}{l}\text { Hosmer and } \\
\text { Lemeshow's Test (p) }\end{array}$ & $4.945(0.763)$ & & & & \\
\hline
\end{tabular}

With regards to nature of infertility, the results from the regression analysis showed that respondents with secondary infertility are less likely to use modern infertility treatment methods compared to those with primary infertility. The odds of respondents with secondary fertility using modern fertility treatment methods compared to those with primary infertility is 0.302 . The results of the regression analysis revealed that respondents who perceived that the cause of infertility is due to health issues are more likely to use modern fertility treatment methods compared to those who perceived that the cause of 
infertility is due to their previous sexual history. The odds of respondents who perceived that the cause of infertility is due to health issues using modern infertility treatment methods compared to those who attributed the cause of infertility to their previous sexual history is 4.706 . With respect to duration of infertility, the Table shows that respondents who had experienced infertility for 11-20 years are more likely to use modern fertility treatment methods compared to those who had experienced infertility for 1-10 years. The odds of respondents who had experienced infertility for 11-20 years using modern infertility treatment methods is 1.587 .

\section{Discussion of Findings}

Statistical tests revealed that nature of infertility is significantly related to treatment seeking behaviour. A woman with primary infertility is more likely to visit a medical doctor before visiting a traditionalist for clarity. The use of both the modern and traditional form of treatment simultaneously was found more among women with primary infertility. The study also discovered that perceived cause of infertility is a significant predictor of treatment seeking behaviour. Perception of infertility influences the treatment options selected by affected women. For instance a woman, who associates her inability to conceive to a spiritual being like a spirit husband as revealed by the herbal care giver in the course of the study, would rather go to a prayer house than visit the hospital. This corroborates previous studies that beliefs about evil spirits and black magic among women informs the perception of infertility among women with unmet fertility needs (Ali, 2006).

The study also revealed that duration of infertility is not a significant predictor of treatment seeking behaviour. This could be attributed to the fact that once the consummation of marriage has taken place without conception regardless of the duration; pressure begins to be mounted on the woman. This corroborates previous study that a woman begins to seek for treatment against infertility as a result of such factors as in-laws' reactions, threat of second wife, love for children, other women's remarks come to play and not necessarily about the duration of the infertility (Nwosu \& Onwe, 2015). On the perceived cause of infertility, the study revealed that infertility can be hereditary through polycystic ovarian syndrome (PCOS). This affects females alone. The carrier is multifactorial. The hereditary pattern though remains uncertain. The study revealed that infertility could be caused by spiritual forces, through eating in the dream or having sexual intercourse with a spirit husband. The study also revealed that the length of the penis and various sexual positions can disrupt the position of the womb. It was also revealed that when the membrane of a pregnant woman is not properly ruptured, it could delay and prevent conception of the next child. On treatment seeking behaviour the study revealed that modern and traditional modes of treatment are used simultaneously by women with unmet fertility needs. This could be because one is used to check the ills of the other. Women with primary infertility were more likely to consult all three (modern, traditional and spiritual) 


\section{Conclusion}

The study was used to ascertain the relationship between these variables (nature of infertility, duration of infertility and perceived cause of infertility) and treatment seeking behaviour. The study concludes that perceived cause of infertility and nature of infertility are significant predictors of treatment seeking behaviour. The study also concludes that the modern and traditional modes of treatment are used simultaneously among women with unmet fertility needs. Both treatment modes complement each other.

\section{Recommendations}

In line with the discussions above, it is therefore recommended that:

1. Understanding the perceived cause of infertility among women can help improve national reproductive health strategies for women.

From the study it was revealed that traditional healers are consulted simultaneously with modern medicine practitioners, we thus recommend the formation of a statutory body to regulate and check the activities of health practitioners (both traditional/modern medicine) in the area of reproductive health.

\section{References}

Abdallah, S. \& Zara, M. (2001) Infertility and social suffering: the case of ART in developing countries. Geneva.

Akanbi, T. (2004) The Attitude of some Nigerians Toward Involuntary Childlessness and its Perceived Psycho-social Effects on the Marital Quality of the affected couples. African Journal of Cross-Cultural Psychology and Sport Facilitation, 6: 1-7.

Aladekomo, F., Oludar, B. \& Ola, T. (2008) Determinants of the choice of treatment outlets for infertility in southwest Nigeria. Rawal Medicine Journal, 33: 193-196.

Ali, T.S. (2006) Health seeking behavior of couples with secondary infertility. Journal of the college of physicians and surgeons-Pakistan, 16: 261-264.

Aluko-Arowolo, S. \& Ayodele, S. (2014) The effects of native culture and religious beliefs on human infertility and assisted reproductive treatment: A focus on the Ijebu people of Nigeria. African Journal of Social Sciences, 4: 88-102.

Araoye, M. (2003) Epidemiology of infertility: Social problems of infertile couples. West African journal of medicine, 22(2): 190-196.

Barden-O'Fallon, J. (2005) Unmet Fertility Expectations and the Perception of Fertility Problems in a Malawian Village. African Journal of Reproductive Health, 9(2): 14-25.

Blundell, R. (2007) Causes of infertility. International Journal of Molecular Medicine and Advances Sciences, 3(1): 63-65.

Boerma, J. (2001) Women and Infertility in Africa: A Multidisciplinary 
Perspective. Amsterdam: Royal Tropical Institute Press.

Boivin J. (1999) Why are infertile patients not using psychosocial counselling. Human Reproduction. 14(5): 1384-1391.

Boivin, J., Bunting, L., Collins, A. \& Nygren, G. (2007) International estimates of infertility prevalence and treatment-seeking: potential need and demand for infertility medical care. Human Reproduction, 22(6): 1506-1512.

Caldwel, J. (1976) Fertility and the household economy in Nigeria. Journal of Comparative Family Studies, 7: 193-253.

Donkor, E. (2009) Coping Strategies of Women Seeking Infertility Treatment in Southern Ghana. African Journal of Reproductive Health, 13(4): 81-94.

Dyer, S.J. (2008) Infertility-related reproductive health knowledge and helpseeking behaviour in African countries. ESHRE Monographs, 1: 29-33.

Ebigbola, J. (2000) National Population Policy: A Viable Option to Human Development. Ibadan: African Bookbuilders.

Greil (2010) The experience of infertility: a review of recent literature. Sociology of health and illness, 32: 140-162.

Hollos, M. \& Larsen, U. (2008) Motherhood in Sub-Saharan Africa: The Social Consequences of Infertility in an Urban Population in Northern Tanzania. Culture, Health \& Sexuality, 10(2): 159-173.

Hollos (2003) Profiles of infertility in southern Nigeria: women's voices from Amakiri. African Journal of Reproductive Health, 7: 46-56.

Ibisomi, L. \& Mudege, N. (2013) Childlessness: perceptions, acceptability and the gender dimension. International union for the scientific study of population, pp. 1-6.

Inhorn, M. \& Van Balen, F. (2002) Infertility around the Globe: New Thinking on Childlessness, Gender and Reproductive Technologies. Berkeley: University of California Press.

Jacob, M. (2003) Frustrated fertility: Infertility and psychological distress among women. Journal of Marriage and Family, 65: 1007-1018.

Johnson-Hanks, J. (2006) Uncertain Honor: Modern Motherhood in an African Crisis. University of Chicago Press.

Kaadaaga, E. (2014) Prevalence and factors associated with herbal medicine among women attending infertility clinic in Uganda. BMC Complementary and Alternative Medicine, pp. 1-6.

Kimani, V. \& Olcnja, J. (2001) Infertility: Cultural dimensions and impact on women in selected communities in Kenya. African Anthropologist, 8: 200214.

Koster-Oyekan, W. (1999) Infertility among Yoruba Women: Perceptions on Causes, Treatments and Consequences. African Journal of Reproductive Health, 3: 13-26.

Leonard, L. (2002) "Looking for Children": the search for fertility among the Sara of southern women in Chad. Med Anthropol, 21: 79-112.

Martins, M. \& Mathews, R. (2001) Living in time: multiple timetables in couples' experiences of infertility and its treatment. In Daly, K. (ed.) Minding the Time in Family Experience: Emerging Perspectives and 
Issues. New York: JAI and Elsevier Science.

Merino, F. (2010) Adoption and Surrogate pregnancy. New York: Infobase.

Mgalla, Z. (1999) Women and Infertility in Sub-Saharan Africa. Reproductive Health Matters, 7(13): 183-188.

Nwosu, I.A. \& Onwe, F. (2015) The plight of infertile women in Nigeria. Journal of Policy and Development Studies, 9(3): 39-46.

Odukogbe, A. (2009). The Impact of Infertility on Infertile Men and Women in Ibadan, Oyo State, Nigeria: A Qualitative Study. African Journal of Reproductive Health, 13(3): 85-98.

Ojua, E. \& Aernyi (2013) Infertility and Gender Difference in reaction Among Couples and Family and Community Treatment: a study of Patients Attending N.K.S.T. Hospital Mkar. European Scientific Journal, 9(32): 93106.

Okonofua, F. (1999) Infertility and Women's Reproductive Health in Africa. African Journal of Reproductive Health, 3(1): 7-12.

Olooto, W., Amballi, A. \& Banjo, T. (2012) A review of Female Infertility; important etiological factors and management. Journal of Microbiology and Biotechnology Research, 2(3): 379-385.

Omage, M.I. (2013) Critical Issues in Marriage Failure in Benin City, Nigeria: Signalling the way forward. European Scientific Journal, 95: 1857-7881.

Orji, E. (2002) Impact of infertility on marital life in Nigeria. International Journal of Gynaecology \& Obstetrics, 79: 61-62.

Oyefara, J.L. (2011) Socio-Cultural Context of Adolescent fertility in Yoruba Society: Insight from Osun State, Nigeria. Concept Publications Limited.

Papreen, N. (2000) Living with Infertility: Experiences among Urban Slum Populations in Bangladesh. Reproductive Health Matters, 8(15): 33-44.

Parry, D. (2005) Women's experience with infertility: Exploring the outcome of empowerment. Women's Studies, 34(2): 191-211.

Peterson, B. (2006) Coping Processes of Couples Experiencing Infertility. Family Relations, 55(2): 227-239.

Remennick, L. (2000) Childless in the land of imperative motherhood: Stigma and coping among infertile Israeli women. Sex Roles, 43: 821-843.

Riessman, C. (2000) Stigma and everyday resistance practices: childless women in South India. Gender and Society, 14(1): 111-135.

Ritzer, G. (2006) Contemporary Social Theory and its Classical Roots: The Basics (second Edition). USA: McGraw-Hill.

Rosenstock, I. (1974) Historical origins of the health belief model. Health Education Monographs, 2: 328-335.

Segen's Medical Dictionary (2016) Fertility treatment. Retrieved from The Free Dictionary: http://medical-dictionary.thefreedictionary.com/fertility+treatment.

Shah, I. (1994) Treatment of infertility: an integral part of reproductive and a necessity. Reproducive Health Matters, 4: 96-97.

Slauson-Blevins, K. (2010) The experience of infertility: a review of recent literature. Sociology of Health \& Illness, 32(1): 140-162. 
Sundby, J. \& Mboge, R. (1998) Infertility in the Gambia: frequency and health care seeking. Soc Sci Med, 46(7): 891-899.

Thompson, C. (2005) Making Parents: The Ontological Choreography of Reproductive Technologies. Cambridge: MA: MIT Press.

Throsby, K. \& Gill, R. (2004) 'It's different for men: masculinity and IVF. Men and Masculinities, 69(4): 330-348.

Tschudin, E. (2010) Correlates of fertility issues in an Internet survey of cancer survivors. Journal of Psychosom Obstetrician Gynaecology, 31: 150-157.

Tsibulsky, I. (2013) Fertility knowledge and beliefs about fertility treatment: findings from the International Fertility Decision-making Study. Human Reproduction, 28(2): 385-397.

Ulrich, M. \& Weatherall, A. (2000) Motherhood and infertility: viewing motherhood through the lens of infertility. Feminism \& Psychology, 10(3): $323-326$.

Umeora, O. (2008) Cultural Misconceptions and Emotional Burden of Infertility in South East Nigeria. The Internet Journal of Gynaecology and Obstetrics, 10(2).

Umezulike, A. \& Efetie, T. (2004) The psychological trauma of infertility in Nigeria. International Journal of Gynaecology \& Obstetrics, 84: 178-180.

Vayena, E., Rowe, P. \& Griffin, D. (2001) Current Practices and Controversies in Assisted Reproduction. New Delhi, India: Byword Editorial Consultants.

Vekemans, M. (1994) Infertility Treatment: Luxury, Desire or Necessity. Motherhood, Fatherhood and Fertility: For Women Who Do and Women Who Don't Have Children. Reproductive Health Matters, 2(4): 93-97.

World Health Organisation [WHO] (2010) Mother or nothing: the agony of infertility. WHO Bulletin, pp. 877-953.

Williams, M. (1997) Toward greater understanding of the psychological effects of infertility on women. Psychotherapy in Private Practice, 16(3): 7-26. 